\title{
Estudo comparativo da toxidez de Palicourea juruana (Rubiaceae) para búfalos e bovinos ${ }^{1}$
}

\author{
Carlos Magno C. de Oliveira², José Diomedes Barbosa², Raquel S. Cavaleiro de \\ Macedo ${ }^{2}$, Marilene de Farias Brito ${ }^{3}$, Paulo Vargas Peixoto ${ }^{4}$ e Carlos Hubinger \\ Tokarnia 4
}

\begin{abstract}
Oliveira C.M.C., Barbosa J.D., Macedo R.S.C., Brito M.F., Peixoto P.V. \& Tokarnia C.H. 2004. [A comparative study of the toxicity of Palicourea juruana (Rubiaceae) to buffalo and cattle.] Estudo comparativo da toxidez de Palicourea juruana (Rubiaceae) para búfalos e bovinos. Pesquisa Veterinária Brasileira 24(1):27-30. Escola de Medicina Veterinária, Campus Castanhal, Universidade Federal do Pará, Rua Maximino Porpino 1000, Castanhal, PA 68743080, Brazil. E-mail: tokarnia@ ufrrj.br

An experimental study was performed to establish the toxicity of Palicourea juruana for buffaloes and to add new data on the toxicity of this plant for cattle. The clinical and pathological pictures were similar, but a comparison of the lethal doses for buffaloes $(1-2 \mathrm{~g} / \mathrm{kg})$ and cattle $(0.25 \mathrm{~g} / \mathrm{kg})$ shows that the buffalo is at least 4 times more resistant. In experiments performed 10 years earlier with the fresh leaves - collected on the same farm in July, at the beginning of the dry season, only 2 months later than in this second experimental series - the lethal dose for cattle was $2 \mathrm{~g} / \mathrm{kg}$. No explanation was found for the extremely high toxicity of the plant observed in the present study.
\end{abstract}

INDEX TERMS: Plant poisoning, Palicourea juruana, Rubiaceae, cattle, buffaloes.

RESUM 0.- 0 estudo foi realizado com os objetivos de estabelecer a sensibilidade dos búfalos a Palicourea juruana e agregar novos dados sobre a toxidez dessa planta para bovinos. Embora os quadros clínico-patológicos tenham sido semeIhantes, a comparação das doses letais para búfalos (entre 1 e $2 \mathrm{~g} / \mathrm{kg}$ ) e para bovinos $(0,25 \mathrm{~g} / \mathrm{kg})$ estabelece o búfalo como pelo menos quatro vezes mais resistente. Em experimentos realizados 10 anos antes - com amostras de $P$. juruana coletadas na mesma fazenda no Pará, em julho de 1993, início da época de seca, portanto apenas 2 meses mais tarde do que os agora realizados em maio de 2003 - a dose letal para bovinos foi de $2 \mathrm{~g} / \mathrm{kg}$. Não encontramos explicação para a toxicidade extremamente elevada da planta verificada nesse estudo.

\footnotetext{
${ }^{1}$ Recebido em 23 de julho de 2003.

Aceito para publicação em 12 de novembro de 2003.

${ }^{2}$ Escola de Medicina Veterinária, Campus Castanhal, Universidade Federal do Pará, Rua Maximino Porpino 1000, Castanhal, PA 68743-080. E-mail: diomedes@ufpa.br

${ }^{3}$ Depto Epidemiologia e Saúde Pública, Instituto de Veterinária, Universidade Federal Rural do Rio de Janeiro (UFRRJ), Km 47, Seropédica, RJ 23851970. E-mail: marilene@ufrri.br

${ }^{4}$ Depto Nutrição Animal e Pastagem, Instituto de Zootecnia, UFRRJ, Seropédica, RJ 23835-000. E-mail: ppeixoto@ ufrrj.br e tokarnia@ ufrrj.br
}

TERMOS DE INDEXAÇÃO: Intoxicação por planta, Palicourea juruana, Rubiaceae, bovinos, búfalos.

\section{INTRODUÇÃO}

As plantas que causam "morte súbita" em bovinos na Região Amazônica (o grupo que causa quase todas as mortes de bovinos intoxicados por plantas naquela região) pertencem às famílias Rubiaceae e Bignoniaceae. Nessa Região, as plantas tóxicas da família Rubiaceae têm como habitat a terra firme, enquanto que as da família Bignonaceae são plantas de várzea. Entre as rubiáceas, Palicourea marcgravii se destaca pela larga distribuição na Região Amazônica. Palicourea juruana e Palicourea grandiflora são menos importantes por terem distribuição bem menor. (Tokarnia et al. 1979, 2000)

Enquanto a toxidez de P. marcgravii tem sido bastante estudada para as diversas espécies animais (Pacheco \& Carneiro 1932, Döbereiner \& Tokarnia 1959, Oliveira 1963, Tokarnia \& Döbereiner 1986, Peixoto et al. 1987, Tokarnia \& et al. 1986, 1991, 1993), inclusive búfalos (Barbosa et al. 2003), ainda há lacunas no conhecimento em relação à toxidez das duas outras rubiáceas.

Os experimentos iniciais sobre a toxidez de P. juruana em bovinos e coelhos foram realizados com as folhas dessecadas 
(Tokarnia \& Döbereiner 1982). Nesses experimentos, seis bovinos, com pesos entre 120 e $154 \mathrm{~kg}$, receberam as folhas dessecadas coletadas em 25.7.78 nas Fazendas Reunidas Ligação, então Município de Paragominas, Pará, nas doses de 0,25 a $2 \mathrm{~g} / \mathrm{kg}$. Os dois bovinos que receberam a dose de $2 \mathrm{~g} / \mathrm{kg}$ morreram. Os dois que receberam a dose de $1 \mathrm{~g} / \mathrm{kg}$ e os que receberam 0,5 e 0,25 g/kg não adoeceram. Dos sete coelhos aos quais foram administradas as folhas dessecadas coletadas na mesma época e no mesmo local, morreram os três que receberam $2 \mathrm{~g} / \mathrm{kg}$; dos três que receberam $1 \mathrm{~g} / \mathrm{kg}$, um morreu, e o que recebeu $0,5 \mathrm{~g} / \mathrm{kg}$ também morreu. Dos dez coelhos adicionais que receberam as folhas dessecadas coletadas no mesmo local, mas em 7.8.77, morreram os que receberam 4 g/kg e 2 g/ $\mathrm{kg}$. Dos quatro coelhos que receberam $1 \mathrm{~g} / \mathrm{kg}$, três morreram e os que receberam $0,5 \mathrm{~g} / \mathrm{kg}$ e $0,25 \mathrm{~g} / \mathrm{kg}$ não adoeceram.

Em 16 e 17.7.1984 realizou-se, em quatro bovinos, com pesos entre 140 e $147 \mathrm{~kg}$, uma outra série de experimentos com as folhas frescas de P. juruana coletadas, em 14.7.1984, na mesma fazenda de Paragominas, nas doses de 0,25 g/kg, $0,5 \mathrm{~g} / \mathrm{kg}, 1,0 \mathrm{~g} / \mathrm{kg}$ e $2 \mathrm{~g} / \mathrm{kg}$. Nesses experimentos só morreu 0 animal que ingeriu $2 \mathrm{~g} / \mathrm{kg}$ das folhas frescas, após intensa movimentação (Tokarnia et al. 1994).

Em relação à toxidez de $P$. juruana para o búfalo, não há dados. De uma maneira geral, os resultados obtidos através de pesquisas em bovinos são aceitos como válidos para búfaIos. Em estudo realizado com P. marcgravii em búfalos, porém, verificou-se que, essa espécie é bem mais resistente que a bovina (Barbosa et al. 2003).

0 presente estudo experimental foi realizado para estabelecer a sensibilidade dos búfalos a P. juruana, compará-la a dos bovinos, e para agregar dados adicionais sobre a toxidez da planta nessa última espécie.

\section{MATERIAL E MÉTODOS}

Neste estudo foram usados quatro búfalos e quatro bovinos, com 1 a 2 anos de idade, todos machos. Os búfalos pesavam entre 183 e 206 $\mathrm{kg}$, os bovinos entre 110 e $225 \mathrm{~kg}$. Os animais eram mantidos em piquete de Brachiaria brizantha, com água à vontade. Aproximadamente 12 horas antes da administração da planta, os animais eram deixados em jejum em um curral. Os exames clínicos e a administração foram feitos em um tronco de contenção. Com relação ao quadro clínico, foram estabelecidas as freqüências cardíaca e respiratória, a freqüência e a intensidade dos movimentos ruminais e a temperatura retal. Quantidades previamente determinadas das fol has frescas de Palicourea juruana eram colocadas na boca dos animais contidos, que prontamente as mastigavam e deglutiam. Em seguida, os animais eram soltos no piquete, onde eram observados. A intervalos de mais ou menos 12 horas os animais eram movimentados durante 15 minutos, geralmente à cavalo, às vezes a pé (ao to do eram movimentados quatro vezes em 48 horas); quando apresentavam sintomas, eram filmadose dentro do possível, examinados clinicamente. Nos casos fatais, imediatamente era realizada a necropsia, com coleta de fragmentos dos principais órgãos em solução de formalina a 10\% para exames histopatológicos. 0 material foi processado rotineiramente e corado pela Hematoxilina-Eosina (HE).

A planta foi coletada em 7 de junho de 2003 nas Fazendas Reunidas Ligação, Município de Ulionópolis, PA, e conservada em geladeira, com exceção do período de 6 horas da viagem de carro, durante a qual foi mantida em saco de pano molhado. Os experimentos foram realizados na Fazenda Curicaca, Município de Castanhal, PA, e se estenderam de 8 a 11 de junho de 2003. Os exames histopatológicos foram realizados no Projeto Sanidade Animal, UFRRJ.

\section{RESULTADOS}

Nos Quadros 1 e 2 consta o delineamento dos experimentos, com dados sobre o desfecho. Pormenores dos experimentos realizados constam nos resumos dos protocolos.

Quadro 1. Intoxicação experimental por Palicourea juruana em búfalos (2003)

\begin{tabular}{|c|c|c|c|c|c|c|c|}
\hline $\begin{array}{l}\text { Identificação } \\
\text { do animal } \\
\text { (reg. SAP) }\end{array}$ & $\begin{array}{l}\text { Peso } \\
(\mathrm{kg})\end{array}$ & $\begin{array}{c}\text { Data da } \\
\text { administração }\end{array}$ & $\begin{array}{l}\text { Dose } \\
(\mathrm{g} / \mathrm{kg})\end{array}$ & $\begin{array}{l}\text { Início de sintomas } \\
\text { leves após começo } \\
\text { da administração }\end{array}$ & $\begin{array}{l}\text { Início de sintomas } \\
\text { graves após começo } \\
\text { da administração }\end{array}$ & $\begin{array}{l}\text { Manifestação } \\
\text { de sintomas } \\
\text { graves ("fase } \\
\text { dramática") }\end{array}$ & Desfecho \\
\hline 5610 & 195 & 09.06 .03 & 0,25 & - & - & - & Sem sintomas \\
\hline 5603 & 183 & 10.06 .03 & 0,50 & - & - & - & Sem sintomas \\
\hline 5604 & 194 & 11.06 .03 & 1,00 & $\begin{array}{l}33 \mathrm{~h} 1 \mathrm{~min} \text { (duran- } \\
\text { te } 5 \mathrm{~h} 44 \mathrm{~min} \text { ) }\end{array}$ & - & - & Sintomas leves \\
\hline $\begin{array}{l}5606 \\
(29642)\end{array}$ & 206 & 08.06 .03 & 2,00 & $8 h 46 \min$ & $11 \mathrm{~h} 02 \mathrm{~min}$ & $5 \mathrm{~min}$. & Morreu \\
\hline
\end{tabular}

Quadro 2. Intoxicação experimental por Palicourea juruana em bovinos (2003)

\begin{tabular}{|c|c|c|c|c|c|c|c|}
\hline $\begin{array}{l}\text { Identificação } \\
\text { do animal } \\
\text { (reg. SAP) }\end{array}$ & $\begin{array}{l}\text { Peso } \\
(\mathrm{kg})\end{array}$ & $\begin{array}{c}\text { Data da } \\
\text { administração }\end{array}$ & $\begin{array}{l}\text { Dose } \\
\text { (g/kg) }\end{array}$ & $\begin{array}{l}\text { Início de sintomas } \\
\text { leves após começo } \\
\text { da administração }\end{array}$ & $\begin{array}{c}\text { Início de sintomas } \\
\text { graves após começo } \\
\text { da administração }\end{array}$ & $\begin{array}{l}\text { Manifestação } \\
\text { de sintomas } \\
\text { graves ("fase } \\
\text { dramática") }\end{array}$ & Desfecho \\
\hline 5632 & 225 & 09.06 .03 & 0,125 & - & - & - & Sem sintomas \\
\hline 5635 (29644) & 122 & 10.06 .03 & 0,250 & $24 \mathrm{~h} 10 \mathrm{~min}$ & $34 \mathrm{~h} 38 \mathrm{~min}$ & $2 \mathrm{~min}$. & Morreu \\
\hline $5636(29645)$ & 110 & 09.06 .03 & 0,50 & $8 \mathrm{~h} 40 \mathrm{~min}$ & $9 \mathrm{~h} 09 \mathrm{~min}$ & $3 \mathrm{~min}$. & Morreu \\
\hline $\begin{array}{c}5634 \\
(29642)\end{array}$ & 110 & 08.06 .03 & 2,0 & - & $8 \mathrm{~h} 04 \mathrm{~min}$ & $2 \mathrm{~min}$. & Morreu \\
\hline
\end{tabular}


No que se refere aos búfalos, verificou-se que as doses de 0,25 e $0,50 \mathrm{~g} / \mathrm{kg}$ não causaram sintomas de intoxicação, a dose de $1,0 \mathrm{~g} / \mathrm{kg}$ causou sintomas leves, e que só a dose de $2,0 \mathrm{~g} / \mathrm{kg}$ determinou a morte. Em relação aos bovinos, só a dose de 0,125 não cursou com sintomas de intoxicação. Doses a partir de 0,25 g/kg causaram a morte de todos os bovinos.

A manifestação clínica mais importante foi a súbita queda do animal ao solo com morte em poucos minutos. Alguns animais, antes desta fase, mostraram sintomas leves, menos óbvios, como relutância em andar e pulso venoso positivo, especialmente quando eram movimentados; estes sintomas leves também foram vistos em animais que ingeriram doses subletais.

O Búfalo 5606 morreu sem ter sido exercitado. Após 8h46min do começo da administração da planta, o animal mostrou sintomas leves, ficando muito tempo em decúbito esternal, às vezes com o pescoço esticado para frente e 0 queixo apoiado no solo. Após 11h02min do começo da administração da planta, de repente o animal caiu, e logo entrou em decúbito lateral, fez movimentos desordenados para ficar em decúbito esternal, sem o conseguir, apresentou opistótono, tinha dispnéia e 5 minutos após ter caído estava morto.

Dos três bovinos que morreram, um (Bov. 5634) morreu sem ter sido exercitado, os dois outros (Bov. 5635 e 5636) mostraram, de repente, graves sintomas que terminaram com a morte, 30 minutos (Bov. 5635) e 9 minutos (Bov. 5636) após os exercícios. Esses dois últimos bovinos, já antes, a partir de 24h10min e 8h40min após o começo da administração da planta, respectivamente, mostraram leves sintomas de intoxicação; o primeiro (Bov. 5635), de início, independentemente de exercício, ficando em decúbito esternal com o pescoço esticado para frente e o queixo apoiado no solo, depois, durante o terceiro exercício, quando correu menos que os outros animais; o segundo (Bov. 5336) durante o primeiro exercício, sob forma de deitar-se rapidamente, com a jugular ingurgitada e pulsando. Os sintomas graves que findaram com a morte dos três bovinos, se iniciaram entre 8 h04min e 34h38min após o começo da administração da planta e tiveram duração de 2 a 3 minutos. Esses sintomas graves consistiram em súbita queda do animal ao solo, ficando logo, ou dentro de pouco tempo, em decúbito lateral, movimentos desordenados, pedalagem e dispnéia.

Os achados de necropsia, tanto no búfalo quanto nos bovinos, foram praticamente negativos. Os exames histopatológicos revelaram, como lesões mais importantes para o búfalo, no rim, degeneração hidrópico-vacuolar das células epiteliais dos túbulos contornados distais, de intensidade discreta, porém nítida, e para os bovinos, vacuolização dos hepatócitos na zona intermediária do lóbulo hepático em dois animais (Bov. 5635 e 5636), e, adicionalmente, no miocárdio de um deles (Bov. 5635), extensas áreas de necrose de coagulação incipiente; no terceiro bovino (Bov. 5634) também foi constatada, no rim, moderada degeneração hidrópico-vacuolar das células epiteliais dos túbulos contornados distais.

\section{Resumo dos protocolos dos experimentos com Palicourea juruana}

Búfalo 5606, macho com $206 \mathrm{~kg}$, recebeu em 8.6.03, das 21:45 às 22:08h, $412 \mathrm{~g}(2 \mathrm{~g} / \mathrm{kg})$ das folhas frescas de Palicourea juruana, colhidas em 7.6.03 nas Fazendas Reunidas Ligação, município de Ulionópolis, PA. Antes da administração temperatura (T) 39.0, freqüência cardíaca por minuto (C) 72, freqüência respiratória por minuto (R) 32 , movimentos ruminais em minutos (Ru) 2/2. Em 9.6.03, às 6:31h, estava deitado em decúbito esternal; durante períodos curtos ficava com a cabeça estendida para frente com o queixo apoiado no solo. Às 7:10 h levantou-se, estimulado pela agitação no início dos trabalhos no curral. Em seguida, solto no piquete, às vezes estava deitado, às vezes em pé, pastando. Às $8: 44 \mathrm{~h}$ assumiu novamente a mesma posição anteriormente referida. Às 8:47, quando novamente em pé, de repente caiu ficando logo em decúbito lateral. Fez movimentos desordenados para ficar em decúbito esternal, porém caiu em decúbito lateral oposto; com opistótono e dispnéia. Às 8:52h estava morto. - Achados de necropsia: sufusões no epicárdio esquerdo junto ao sulco coronário longitudinal. Pequena quantidade de líquido citrino no saco pericárdico. - Os exames histopatológicos (SAP 29642) revelaram no pulmão moderada congestão difusa e no rim, discreta, porém nítida degeneração hidrópico-vacuolar das células epiteliais dos túbulos contornados distais.

Bovino 5635, macho com $122 \mathrm{~kg}$, recebeu em 10.6.03, das 22:20 às $22: 23 \mathrm{~h}, 30,5 \mathrm{~g}(0,25 \mathrm{~g} / \mathrm{kg})$ das folhas frescas de P. juruana, colhidas em 7.6.03 nas Fazendas Reunidas Ligação, min. Ulionópolis, PA. Antes da administração, T 30.7, C 84, R 36, Ru 2/2. Em 11.6.03, às 22:30h, estava em decúbito esternal, com o pescoço esticado para frente e o queixo apoiado no solo. Em 12.6.03, às 7:30h, novamente foi observado nesta posição. Das 8:13 às 8:28h, quando foi exercitado, correu menos do que os outros animais. Às 8:58h, quando em estação, de repente se desequilibrou, deu alguns passos para frente pendendo para a direita e caiu encostado à cerca, ficando parcialmente em decúbito lateral e às 9:00h estava morto. - Achados de necropsia: Fígado ao corte levemente alaranjado. - Os exames histopatológicos (SAP 29644) revelaram, no fígado, moderada vacuolização dos hepatócitos na região intermediária do lóbulo hepático e na região centrolobular, um pouco menos intensa; no miocárdio havia extensas áreas de necrose de coagulação das fibras cardíacas (incipiente), caracterizada por citoplasma mais eosinófilo que o normal, às vezes vacuolizado e núcleo com cromatina condensada.

Bovino 5634, macho com $110 \mathrm{~kg}$, recebeu em 8.6.03, das 21:30 às 21:37h, $220 \mathrm{~g}(2 \mathrm{~g} / \mathrm{kg})$ das folhas frescas de P. juruana, colhidas em 7.6.03 nas Fazendas Reunidas Ligação, mun. Ulionópolis, PA. Antes da administração, T 39.0, $\mathrm{C} 80, \mathrm{R} 28$, Ru 2/2. Em 9.6.03, às 5:34h, quando estava em pé, de repente caiu e ficou logo em decúbito lateral, fez poucos movimentos de pedalagem, colocou a cabeça em opistótono, entrou em dispnéia e às 5:36h estava morto. - Achados de necropsia: Fígado, ao corte, levemente alaranjado. - Os exames histopatológicos (SAP 29643) revelaram, no rim, moderada degeneração hidrópico-vacuolar das células epiteliais dos túbulos contornados distais.

Bovino 5636, macho com $110 \mathrm{~kg}$, recebeu em 9.6.03, das 7:20 às 7:28h, 55 $\mathrm{g}(0,5 \mathrm{~g} / \mathrm{kg})$ das folhas frescas de P. juruana, colhidas em 7.6.03 nas Fazendas Reunidas Ligação, mun. Ulionópolis, PA. Antes da administração, T 38.9, C 84, R 52 , Ru 2/0. No mesmo dia, às 16:00h, 3 minutos após o início do exercício, deitou rapidamente; logo em seguida levantou-se, urinou, a jugular estava ingurgitada e pulsando. Correu bem, mas às 16:05h deitou-se rapidamente, com a jugular bem saliente, pulsando. Às $16: 20 \mathrm{~h}$, fim do exercício, ficou em pé, parado. Às 16:29h, isto é, 9 minutos após o fim do exercício, quando tinha andado um pouco, de repente mostrou instabilidade e caiu em decúbito esternal, fez movimentos desordenados com o pescoço (cabeça), tinha a respiração ofegante, passou ao decúbito lateral, com a respiração ofegante, fez movimentos de pedalagem, mugiu diversas vezes e às 16:32h estava morto. - Achados de necropsia: Sem alterações. - Os exames histopatológicos (SAP 29645) revelaram, no fígado, moderada vacuolização dos hepatócitos na zona intermediária do lóbulo.

\section{DISCUSSÃO E CONCLUSÕES}

Demonstrou-se que o búfalo também é sensível à intoxicação por Palicourea juruana. 0 quadro clinico-patológico observado nessa espécie é semelhante ao visto em bovinos. Verificou-se 
que, na intoxicação por P. juruana, assim como na por outras plantas tóxicas que causam "morte súbita", também ocorre, no rim, degeneração hidrópico-vacuolar das células epiteliais dos túbulos contornados distais; esta alteração ainda não tinha sido anteriormente registrada na intoxicação por P. juruana. Pelos experimentos realizados pode-se concluir que os búfalos são, pelo menos, 4 vezes mais resistentes que os bovinos à ação tóxica de Palicourea juruana, semelhante ao verificado em relação a Palicourea marcgravii para essa espécie (Barbosa et al. 2003). Os sintomas que precedem o desfecho da intoxicação por plantas que causam "morte súbita", referido como "fase dramática da intoxicação" (Tokarnia et al. 2000), foram mais evidentes e prolongados no caso de intoxicação por P. juruana em búfalos do que em bovinos.

Um aspecto que surpreendeu nesses últimos experimentos realizados com $P$. juruana em bovinos, foi a dose letal muito baixa, bem diferente do que foi observado anteriormente. Enquanto nos experimentos realizados em bovinos, em 1978 e 1984 (Tokarnia \& Döbereiner 1982, Tokarnia et al. 1994), a planta era bem menos tóxica que P. marcgravii, em 2003 ela foi mais tóxica. Não sabemos qual o motivo desta variação, pois a planta foi coletada na mesma fazenda, aproximadamente na mesma época do ano (em 1978 em 25 de agosto, em 1984 em 14 de julho e em 2003 em 7 de junho), sempre no fim da época de chuvas e início da época de seca. Os pesos dos bovinos experimentais em 1978 variaram entre 113 e 154 kg, em 1984 entre 140 e $147 \mathrm{~kg}$ e em 2003 entre 110 e 225 (entre 110 e 125 para três bovinos que morreram, pesando o quarto que recebeu a menor dose e não morreu, $225 \mathrm{~kg}$ ), portanto com uma única exceção, eram semelhantes, e por isto não devem ter influenciado o resultado dos experimentos. Não foi possível esclarecer a grande divergência entre estes dados. Esses resultados indicam que P. juruana, sob condições ainda não esclarecidas, pode ser mais tóxica que P. marcgravii.

\section{REFERÊNCIAS}

Barbosa J.D., Oliveira C.M.C., Tokarnia C.H. \& Riet-Correa F. 2003. Comparação da sensibilidade de bovinos e búfalos à intoxicação por Palicourea marcgravii (Rubiaceae). Pesq.Vet.Bras. 23(4):167-172.

Döbereiner J. \& Tokarnia C.H. 1959. Intoxicação de bovinos pela "erva de rato" (Palicourea marcgravii St. Hil.) no vale do Itapicuru, Maranhão. Arqs Inst. Biol. Animal, Rio de J., 2:83-91.

Oliveira M.M. 1963. Chromatographic isolation of monofluoroacetic acid from Palicoura marcgravii St. Hil. Experientia 19:586.

Pacheco G. \& Carneiro V. 1932. Estudos experimentais sobre plantas tóxicas. I. Intoxicação dos animais pela "erva de rato da mata". Revta Soc. Paulista Med. Vet. 2(2-3):23-46.

Peixoto P.V., Tokarnia C.H., Döbereiner J. \& Peixoto C.S. 1987. Intoxicação experimental por Palicourea marcgravii (Rubiaceae) em coelhos. Pesq. Vet. Bras. 7(4):117-129.

Tokarnia C.H. \& Döbereiner J. 1986. Intoxicação por Palicourea marcgravii (Rubiaceae) em bovinos no Brasil. Pesq. Vet. Bras. 6(3):73-92.

Tokarnia C.H., Döbereiner J. \& Silva M.F. 1979. Plantas Tóxicas da Amazônia a Bovinos e outros Herbívoros. INPA, Manaus. 95 p.

Tokarnia C.H. \& Döbereiner J. 1982. Intoxicação experimental por Palicourea juruana (Rubiaceae) em bovinos e coelhos. Pesq. Vet. Bras. 2(1): 17-26.

Tokarnia C.H., Döbereiner J. \& Peixoto P.V. 1994. Aspectos clínico-patológicos complementares da intoxicação por algumas plantas tóxicas brasileiras. Pesq. Vet. Bras. 14(4): 111-122.

Tokarnia C.H., Peixoto P.V. \& Döbereiner J. 1986. Intoxicação experimental por Palicourea marcgravii (Rubiaceae) em ovinos. Pesq. Vet. Bras. 6(4):121131.

Tokarnia C.H., Peixoto P.V. \& Döbereiner J. 1991. Intoxicação experimental por Palicourea marcgravii (Rubiaceae) em caprinos. Pesq. Vet. Bras. 11(3/ 4):65-70.

Tokarnia C.H., Costa E.R., Barbosa J.D., Armién A.G. \& Peixoto P.V. 1993. Intoxicação experimental por Palicourea marcgravii (Rubiaceae) em eqüinos. Pesq. Vet. Bras. 13(3/4): 67-72.

Tokarnia C.H., Döbereiner J. \& Peixoto P.V. 2000. Plantas Tóxicas do Brasil. Editora Helianthus, Rio de Janeiro. 310 p. 